\title{
APLIKASI AKUNTANSI PENCATATAN PENERIMAAN KAS PADA PT. MEGA VISION MANDIRI
}

\author{
Ahmad Baihaqi Amir Amrullah', Widya Jati Lestari², Wanda Ilham ${ }^{3}$ \\ Universitas Catur Insan Cendekia \\ Jl. Kesambi No. 202, Cirebon \\ e-mail: ahmadbaihaqi067@gmail.com ${ }^{1}$,widya.jatilestari@cic.ac.id², wandailham@cic.ac.id ${ }^{3}$
}

\begin{abstract}
ABSTRAK
PT. Mega Vision Mandiri adalah perusahaan yang bergerak dibidang telekomunikasi dan komunikasi yang memberikan layanan kepada masyarakat dengan memberikan tayangan televisi dengan audio visual berkualitas jernih. Dengan memberikan tayangan-tayangan yang bermutu dan mendidik, Seperti channel be In Sport 1, Fox Family Movies, Discovery Channels dan Makkah Live. Tayangan televisi yang diberikan oleh perusahaan kepada pelanggan sangat diharapakan bisa dapat mendidik dan juga mencerdaskan masyarakat di era globalisasi seperti sekarang ini. Perusahaan ini adalah wadah bagi para pengusaha tv kabel yang berskala kecil di wilayah Kuningan khususnya di daerah Kadugede yang kebanyakan masih ilegal. Dengan adanya pengusaha tv kabel yang bergabung,maka PT. Mega Vision Mandiri memerlukan sistem untuk mencatat penerimaan kas dengan baik, sehingga dapat memberikan laporan mengenai kinerja perusahaan, dan dapat melihat data keuntungan sesuai dengan yang diharapkan oleh perusahaan. Sistem yang digunakan saat ini oleh perusahaan masih menggunakan aplikasi microsft excel, oleh karena itu dengan dibuatkannya Aplikasi Akuntansi Pencatatan Penerimaan Kas yang berbasis web ini , dapat memudahkan perusahaan dalam hal mencatat data pelanggan milik pengusaha tv kabel yang bergabung dan juga untuk memudahkan perusahaan dalam mencatat penerimaan kas masuk ke perusahaan. Laporan yang dihasilkan dari aplikasi ini berupa data nama pengusaha tv kabel, data pelanggan, jurnal umum dan laporan pencatatan penerimaan kas.
\end{abstract}

Kata Kunci : Aplikasi, Penerimaan, Kas Masuk

\begin{abstract}
PT. Mega Vision Mandiri is a company engaged in telecommunication and communication that provides services to the public by providing television shows with clear audio visual quality. By providing quality and educational shows, such as the Be In Sport 1 channel, Fox Family Movies, Discovery Channels and Makkah Live. It is hoped that the television broadcasts provided by the company to customers can educate and also educate the public in this era of globalization. This company is a forum for small-scale cable tv entrepreneurs in the Kuningan area, especially in the Kadugede area, most of which are still illegal. With the cable tv entrepreneurs joining, PT. Mega Vision Mandiri requires a system to record cash receipts properly, so that it can provide reports on company performance, and can see profit data as expected by the company. The system currently used by the company still uses the Excel microsft application, therefore with the creation of this web-based Cash Receipt Accounting Application, it can make it easier for companies to record customer data belonging to cable tv entrepreneurs who join and also to make it easier for companies to record receipts. cash goes to the company. The reports generated from this application are in the form of data on the names of cable tv entrepreneurs, customer data, general journals and reports on recording cash receipts.
\end{abstract}

Keywords: Applications, Receipts, Cash In

JURNAL DIGIT Vol. 11, No.1 Mei 2021, pp.101 110 


\section{PENDAHULUAN}

PT. Mega Vision Mandiri adalah perusahaan yang bergerak di bidang telekomunikasi yang memberikan layanan kepada masyarakat dengan memberikan tayangan televisi dengan audio visual dan gambar yang berkualitas jernih. Dengan memberikan tayangan-tayangan yang bermutu seperti channel beIn Sport 1, Fox Family Movies, Discovery Channels dan Makkah Live. Diharapakan dapat mendidik dan juga mencerdaskan masyarakat di era globalisasi seperti sekarang ini. Perusahaan ini adalah wadah bagi para pengusaha tv kabel berskala kecil di wilayah kuningan khususnya di daerah kadugede. Dengan berinduknya pengusaha tv kabel pada perusahaan, mereka tidak lagi takut dengan adanya kegiatan razia yang sering kerap terjadi dilakukan oleh perusahaan stasiun televisi yang merasa sangat dirugikan, karena para pengusaha tv kabel mendistribusikan channel tv mereka ke pelanggan tanpa sepengetahuan dan izin dari perusahaan stasiun tersebut.

Dengan adanya pengusaha tv kabel yang bergabung dengan PT Mega Vision Mandiri, maka perusahaan sangat memerlukan sistem untuk mengatur, mengontrol dan mengelola pengusaha tv kabel dalam hal pencatatan peneriman kas agar menghasilkan keuntungan yang di inginkan oleh perusahaan, Perusahaan sangat memerlukan catatan data pelanggan milik pengusaha tv kabel, karena jumlah penerimaan kas yang diterima perusahaan ditentukan oleh jumlah pelanggan yang dimiliki oleh pengusaha tv kabel dan pengusaha tv kabel tersebut mempunyai jumlah pelanggan yang berbeda-beda.

Berdasarkan uraian latar belakang tersebut dan pentingnya sistem akuntansi penerimaan kas di PT Mega Vision Mandiri maka penelitian ini diberi judul "Aplikasi Akuntansi Pencatatan Penerimaan Kas Pada PT. Mega Vision Mandiri ".

\section{KAJIAN PUSTAKA}

\subsection{Aplikasi}

Menurut Eriek Orlando (2017) Bila dimaknai secara istilah, aplikasi adalah suatu program yang siap untuk digunakan yang dibuat untuk melaksanakan suatu fungsi bagi pengguna jasa aplikasi serta penggunaan aplikasi lain yang dapat digunakan oleh suatu sasaran yang akan dituju. Aplikasi komponen yang berguna melakukan pengolahan data maupun kegiatan - kegiatan seperti pembuatan dokumen atau pengolahan data. Aplikasi adalah penggunaan dalam suatu komputer, instruksi atau pernyataan yang disusun sedemikian rupa sehingga komputer dapat memproses input menjadi output.

\subsection{Akuntansi}

Menurut Ni Wayan Esteria (2016) Akuntansi adalah sebagai proses pengidentifikasian, pengukur dan melaporkan informasi ekonomi untuk memungkinkan adanya penilaian - penilaian dan keputusan yang jelas dan tegas bagi mereka yang menggunakan informasi tersebut.

\subsection{Penerimaan Kas}

Menurut Mulyadi (2016) Penerimaan kas bisa berasal dari berbagai macam sumber yaitu dari penjualan tunai, penjualan aktiva tetap, pinjaman baik dari bank maupun wesel, setoran modal baru. Tetapi penerimaan kas perusahaan biasanya berasal dari 2 (dua) sumber utama yaitu penerimaan kas dari penjualan tunai dan penerimaan kas dari piutang.

\subsection{Flowmap}

Menurut Mulyadi (2016) Sistem akuntansi dapat dijelaskan dengan menggunakan bagan alir dokumen. Untuk menggambarkan aliran dokumen dalam sistem tertentu, digunakan simbol-simbol dalam suatu bagan alir dokumen (document flowchart).

\section{METODE PENELITIAN}

\subsection{Metode}

\subsubsection{Metode Waterfall}

Metode yang diterapkan pada penelitian ini adalah metode waterfall dimana terdapat lima tahapan yang dijelaskan pada gambar 1 dibawah ini. 


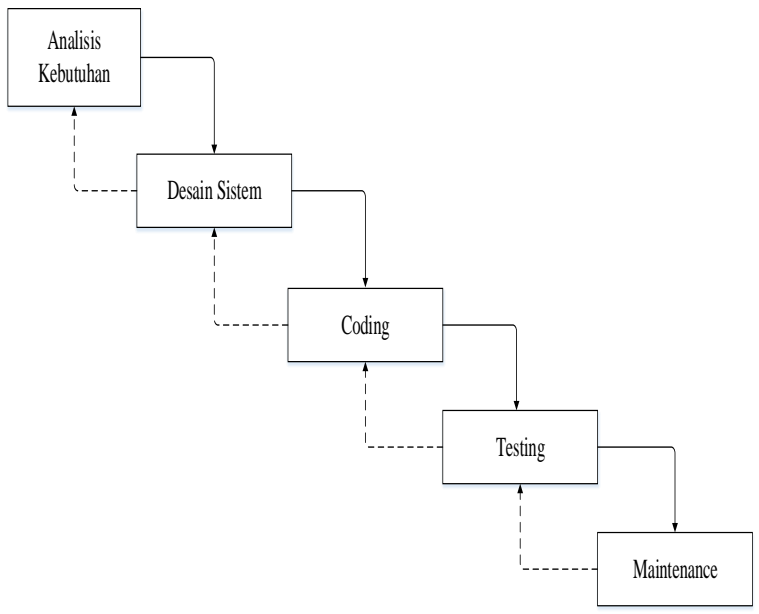

Gambar 1. Metode Waterfall

Penjelasan dari gambar diatas dijelaskan dibawah ini sebagai berikut.

1. Analisis Kebutuhan

Tahap analisis kebutuhan dilakukan dengan menganalisa kebutuhan user, analisa perangkat lunak dan perangkat keras yang dibutuhkan dalam pengembangan sistem serta kebutuhan lain dalam pembuatan basis data. Analisa kebutuhan perangkat lunak yang membantu pembuatan sistem ini yaitu Sistem Operasi XAMPP versi 1.7.3, Bahasa pemrograman PHP dan MySQL.

2. Desain Sistem

Tahap selanjutnya yaiitu mendesain sistem. Tahap ini dibuat sebelum tahap pengkodean. Tujuan dari tahap ini adalah memberikan gambaran tentang apa yang akan dikerjakan dan bagaimana tampilannya. Tahap ini memenuhi semua kebutuhan penggunaan sesuai dengan hasil yang dianalisa seperti sistem aplikasi penjualan tunai di PT. Mega Vision Mandiri. Dokumentasi yang dihasilkan dari tahap desain sistem ini antara lain perancangan flowmap, diagram konteks, data flow diagram (DFD), Entity Relation ship (ERD), dan perancangan interface.

3. Coding (Penulisan Kode Program)

Aktivitas pada tahap ini dilakukan pengkodean sistem. Penulisan kode program merupakan tahap penerjemahan desai sistem yang telah dibuat ke dalam bentuk perintah-perintah yang dimengerti komputer dengan menggunakan bahas pemrograman. Tahap ini merupakan tahapan secara nyata dalam mengerjakan suatu sistem. Dalam sistem ini Bahasa pemrograman yang dipakai adalah PHP dan database MySQL.

4. Testing (Pengujian Program)

Pengujian dilakukan untuk memastikan bahwa software yang dibuat telah sesuai dengan desain sistem yang sudah dirancang dan semua fungsi dapat dipergunakan dengan baik tanpa ada kesalahan.

5. Operation and Maintenance (Pemeliharaan Program)

Tahap ini merupakan tahap terakhir dalam metode waterfall. Sistem dapat di implementasikan pemeliharan mencakuo koreksi dari berbagai error yang tidak ditemukan pada tahap-tahap terdahulu, perbaikan atas implementasi dan pengembangan unit sistem, serta pemeliharaan program. Pemeliharaan sistem dapat dilakukan oleh seorang administrator untuk meningkatkan kualitas sistem agar lebih baik.

\subsubsection{Penelitian Lapangan}

Penelitian Lapangan adalah metode pengumpulan data dengan cara mengamati langsung objek yang diteliti, adapun teknik pengumpulan data yang digunakan adalah sebagai berikut :

a) Observasi

Observasi adalah teknik yang dilaksanakan dengan mengadakan penelitian langsung secara teliti, terlibat dalam kegiatan dan pencatatan secara sistematis.

b) Wawancara

Wawancara adalah suatu metode atau teknik yang digunakan untuk mendapatkan data yang diperlukan dalam penyelesaian penelitian ini. 
3.1.3 Penelitian Jurnal Ilmiah

Penelitian jurnal ilmiah adalah metode pengumpulan data dengan cara mencari informasi dengan membaca jurnal ilmiah yang berkaitan dengan tujuan memperoleh data yang bersifat teori.

\subsection{Flowchart}

Dalam bagan alir, arus dokumen digambarkan berjalan dari kiri ke kanan dan dari atas ke bawah. Arah perjalanan dokumen ini dapat diikuti dengan melihat nomor dalam simbol penghubung pada halaman yang sama (on-page connector) atau nomor dalam simbol penghubung pada halaman yang berbeda (off-page connector).

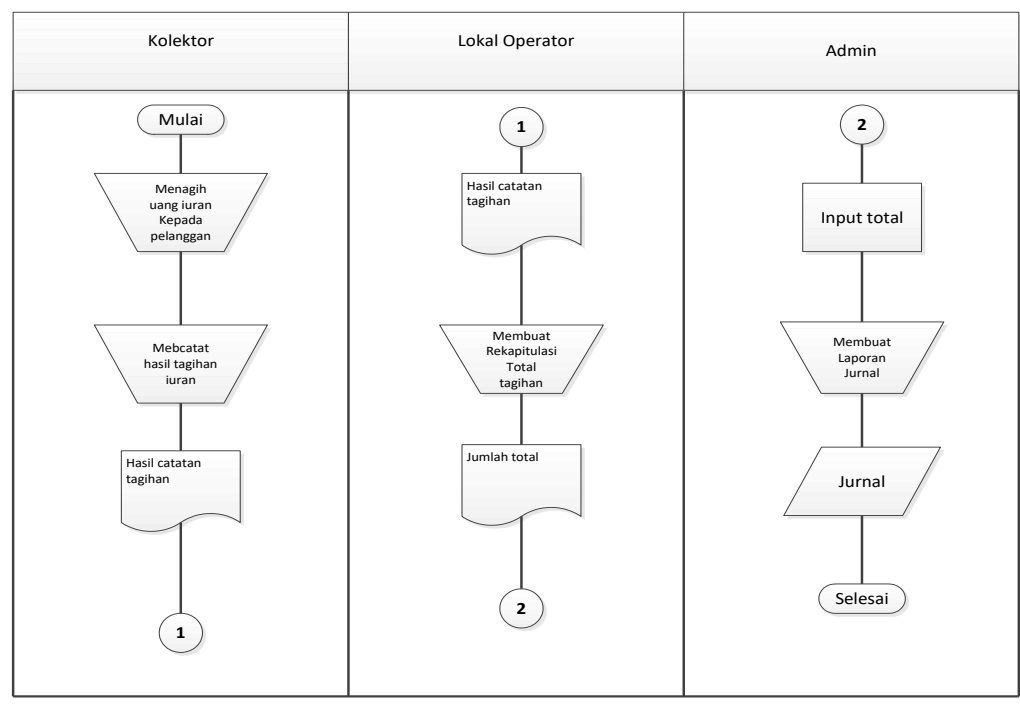

Gambar 2. Flowchart

\subsection{Flowmap}

Flowmap pada penelitian ini dapat dijelaskan pada gambar 3 dibawah ini.

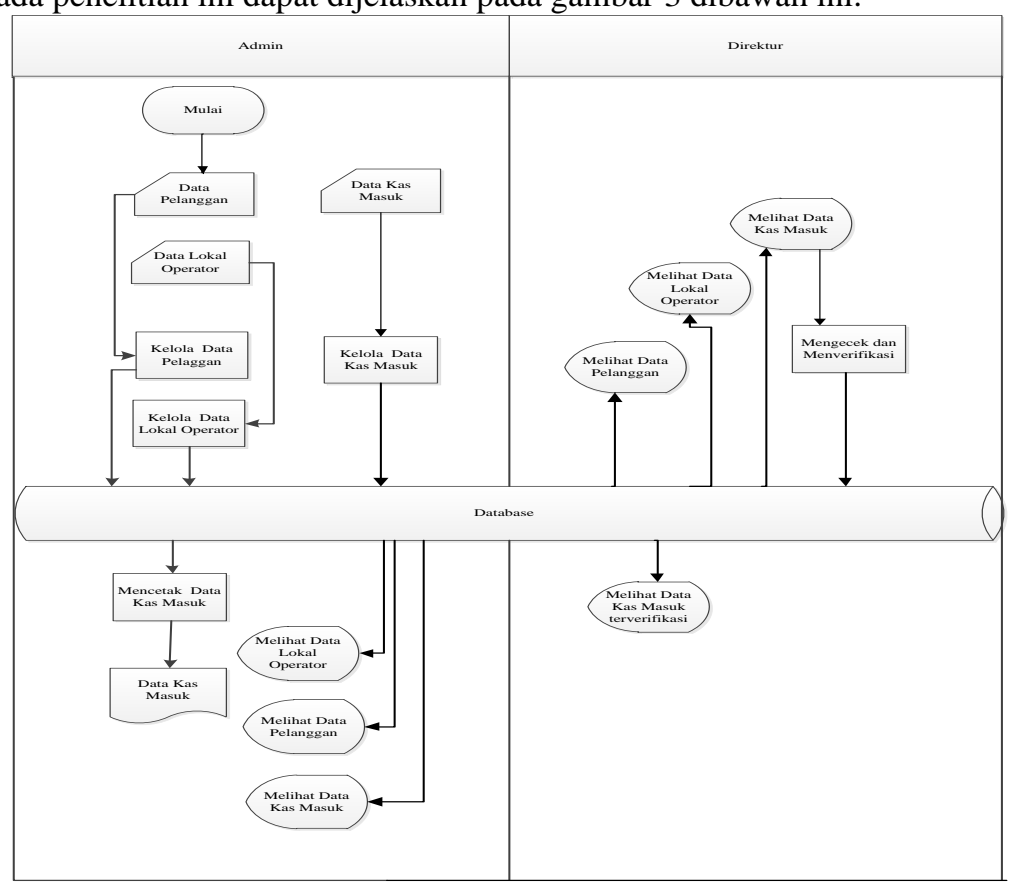

Gambar 3. Flowmap

Aplikasi Akuntansi Pencatatan Penerimaan Kas Pada PT. Mega Vision Mandiri (Ahmad Baihaqi Amir Amrullah, Widya Jati Lestari, Wanda Ilham) 


\section{Implementasi Dan Pengujian Sistem}

\subsection{Tampilan Awal}

\subsubsection{Form Login}

Form Login yaitu form yang di gunakan oleh user untuk mengakses program aplikasi tersebut berdasarkan hak akses yang di dapat dari kebijakan perusahaan sebagai pemakai aplikasi.
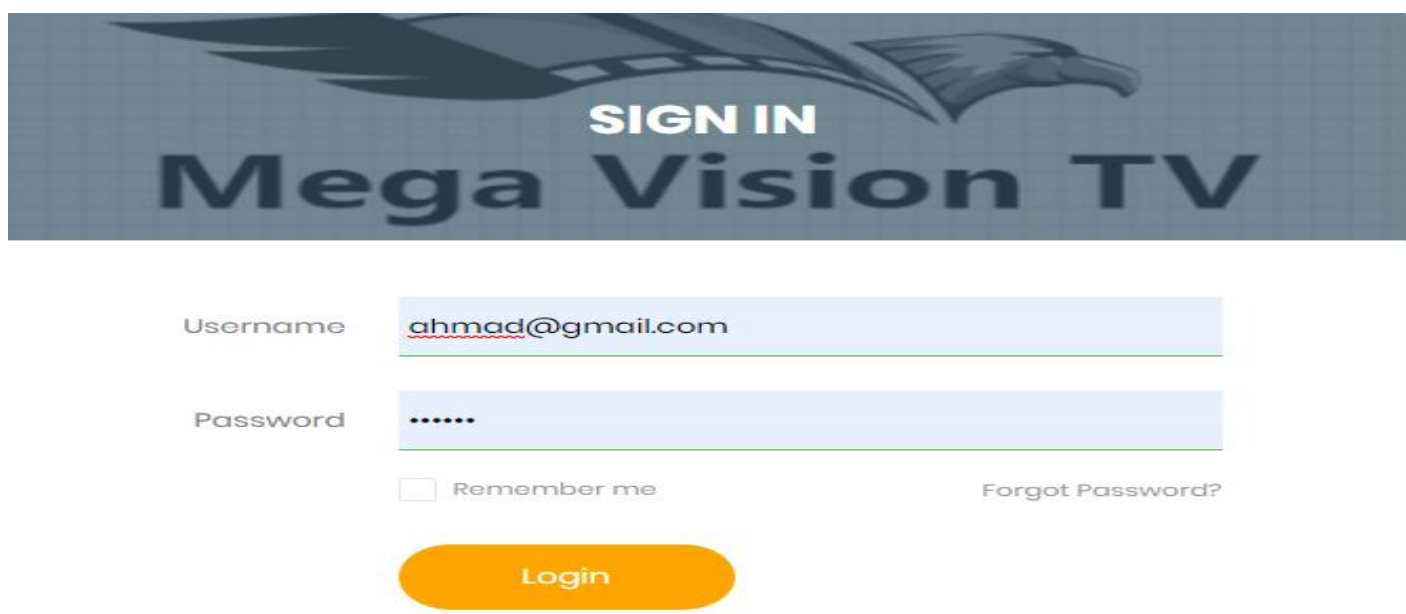

Gambar 4. Form Login

\subsection{Tampilan Bagian Admin}

\subsubsection{Tampilan Input Data Lokal Operator}

Form Menu input data lokal operator yaitu form yang di gunakan oleh bagian Admin untuk menambahkan data lokal operator.

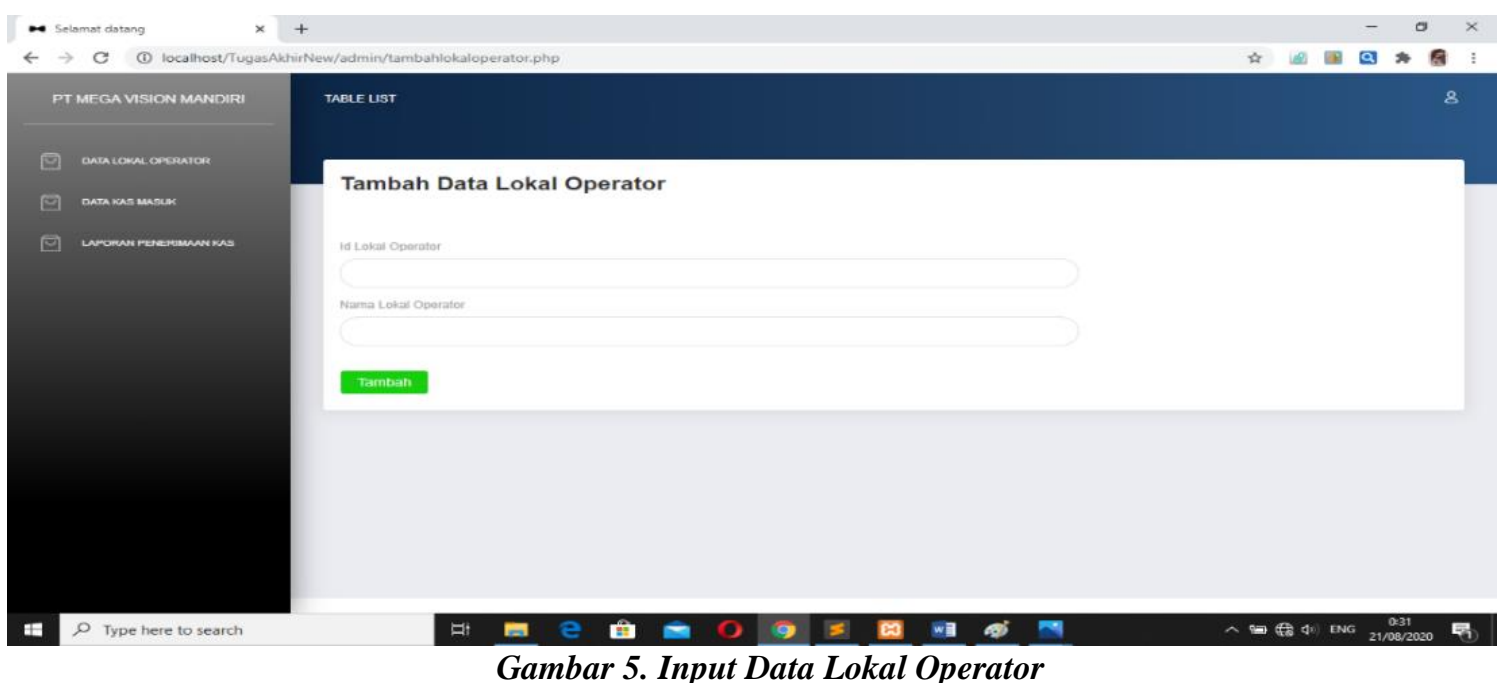

\subsubsection{Tampilan List Data Lokal Operator}

List data lokal operator yaitu form yang di gunakan oleh bagian Admin untuk menginput data lokal operator, mengedit data lokal operator dan menghapus data lokal operator. 


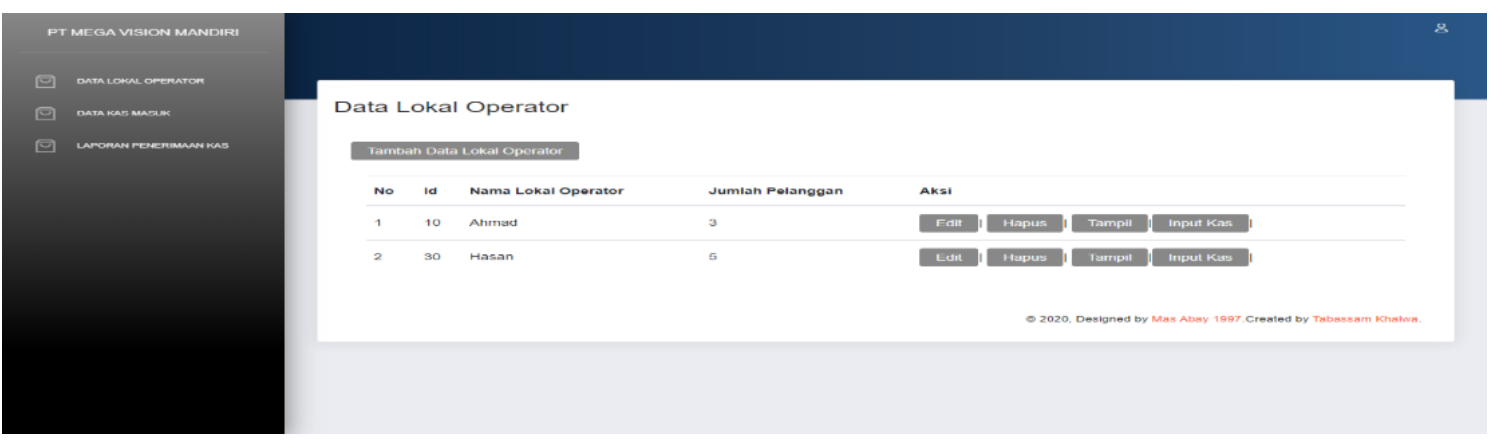

Gambar 6. List Data Lokal Operator

\subsubsection{Tampilan List Data Pelanggan}

Menu Tampilan data pelanggan yaitu tampilan yang di gunakan oleh bagian Admin untuk melihat data pelanggan.

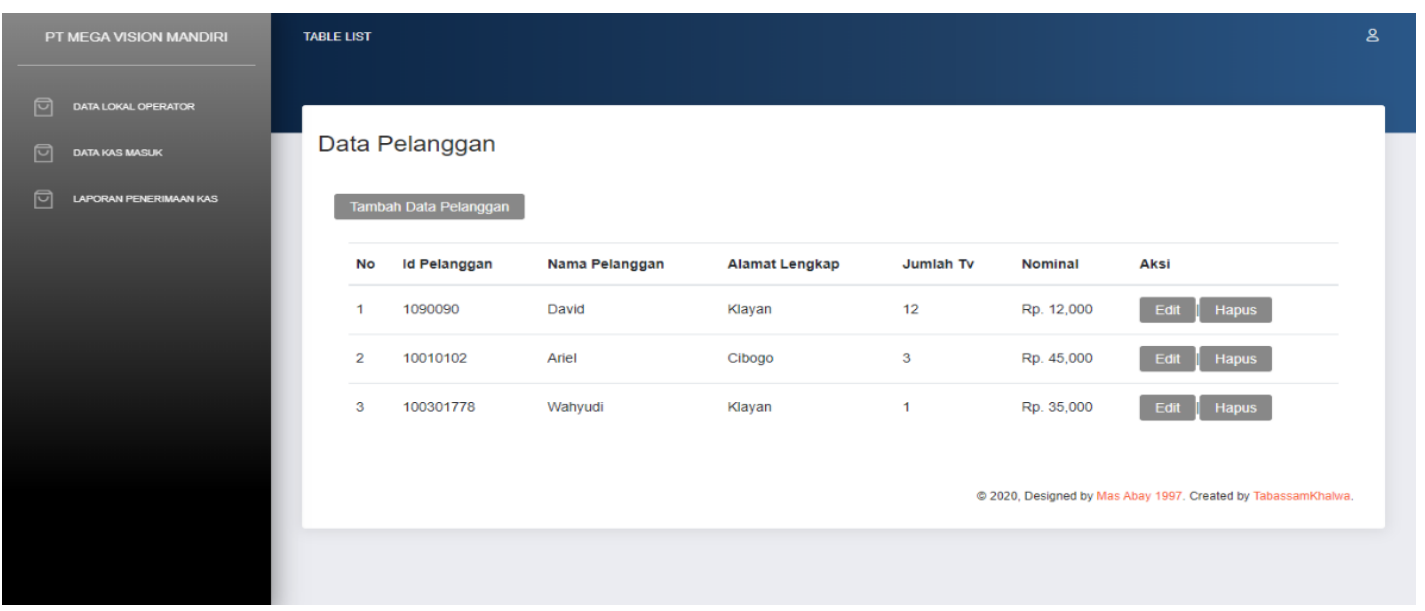

Gambar 7. List Data Pelanggan

\subsubsection{Tampilan Tambah Data Pelanggan}

Tampilan Form Menu Tambah Data Pelanggan yaitu form yang di gunakan oleh bagian Admin untuk menambahkan data pelanggan.

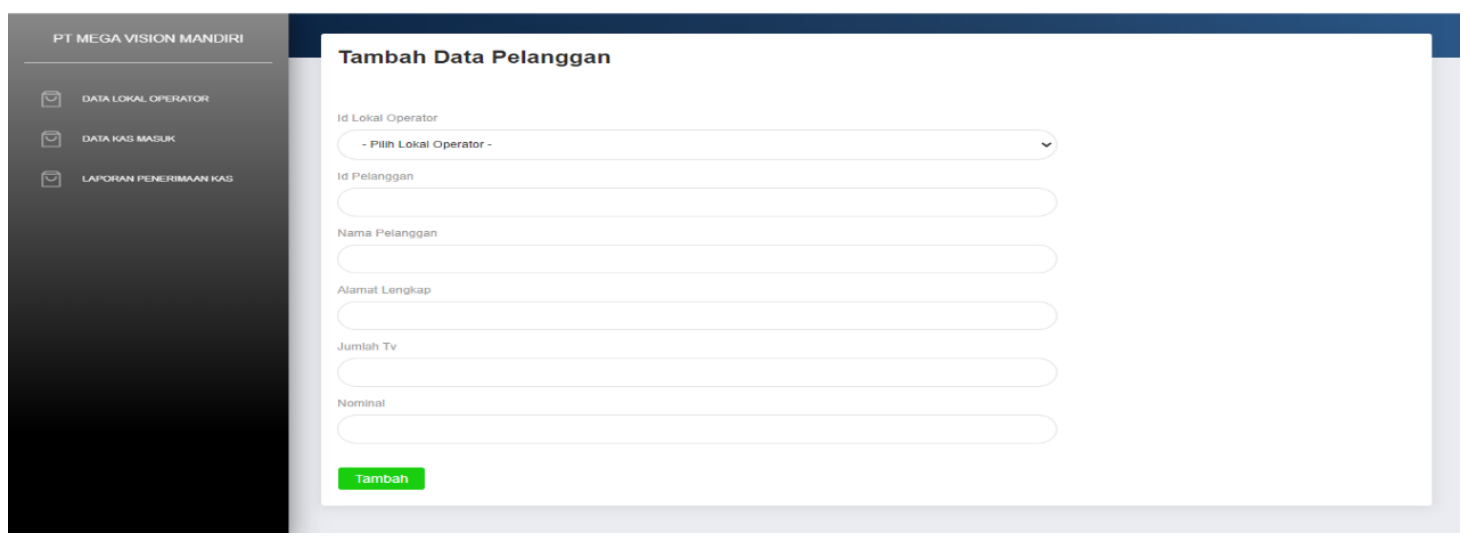

Gambar 8. Tampilan Form Tambah Data Pelanggan

Aplikasi Akuntansi Pencatatan Penerimaan Kas Pada PT. Mega Vision Mandiri (Ahmad Baihaqi Amir Amrullah, Widya Jati Lestari, Wanda Ilham) 


\subsubsection{Tampilan Kas Masuk}

Menu Tampilan Kas Masuk yaitu form yang di gunakan oleh bagian Admin untuk menginput data kas masuk.

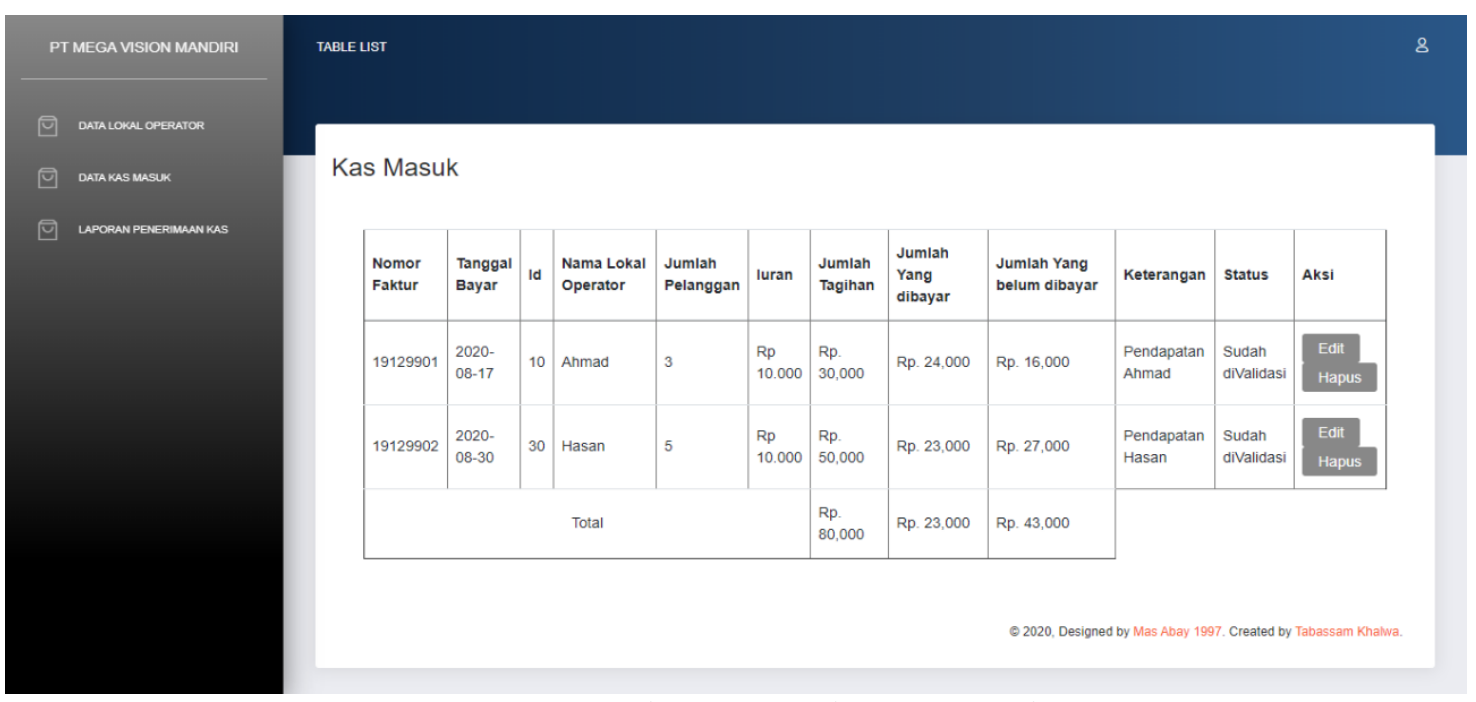

Gambar 9. Tampilan Kas Masuk

\subsubsection{Tampilan Input Kas Masuk}

Form Menu Tampilan Kas Masuk yaitu form yang di gunakan oleh bagian Admin untuk menginput data kas masuk.

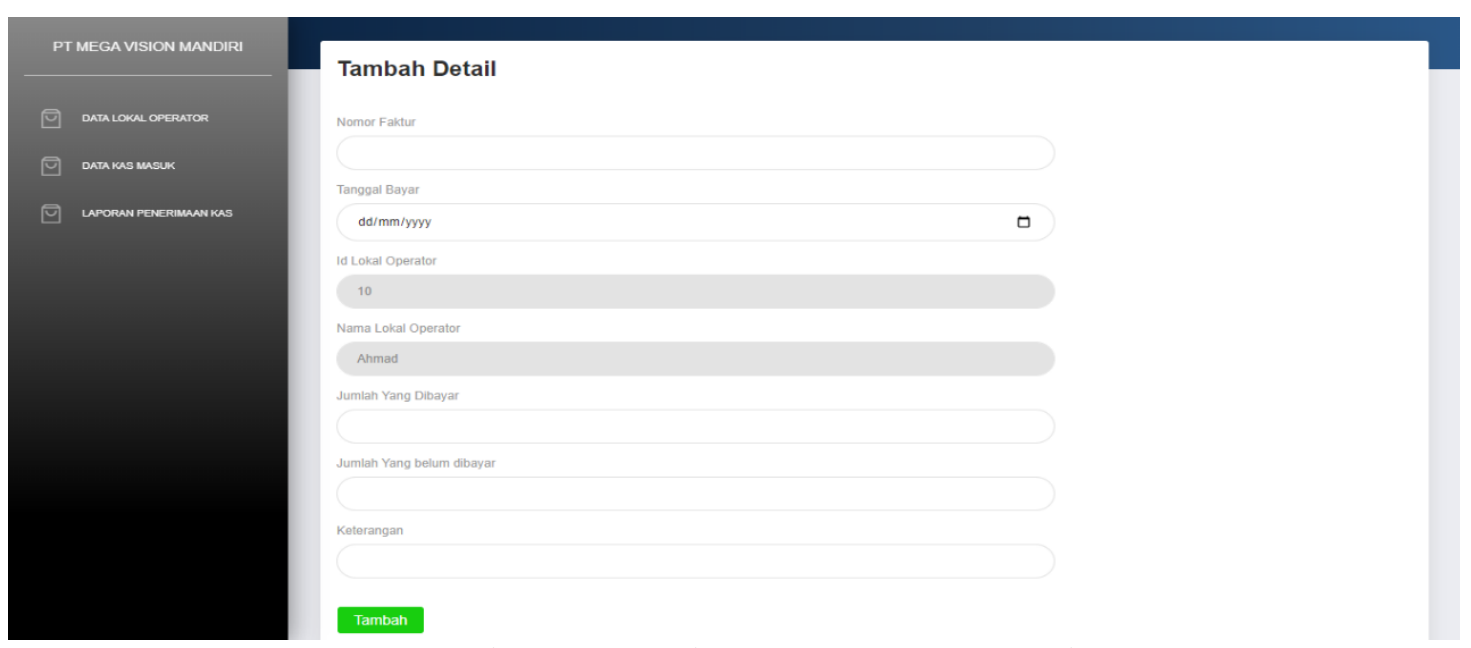

Gambar 10. Tampilan Form Input Kas Masuk 


\subsubsection{Tampilan Bagian Direktur}

Tampilan Menu Data Lokal Operator Tani yaitu tampilan yang di gunakan oleh bagian direktur untuk melihat dan mengecek data lokal operator.

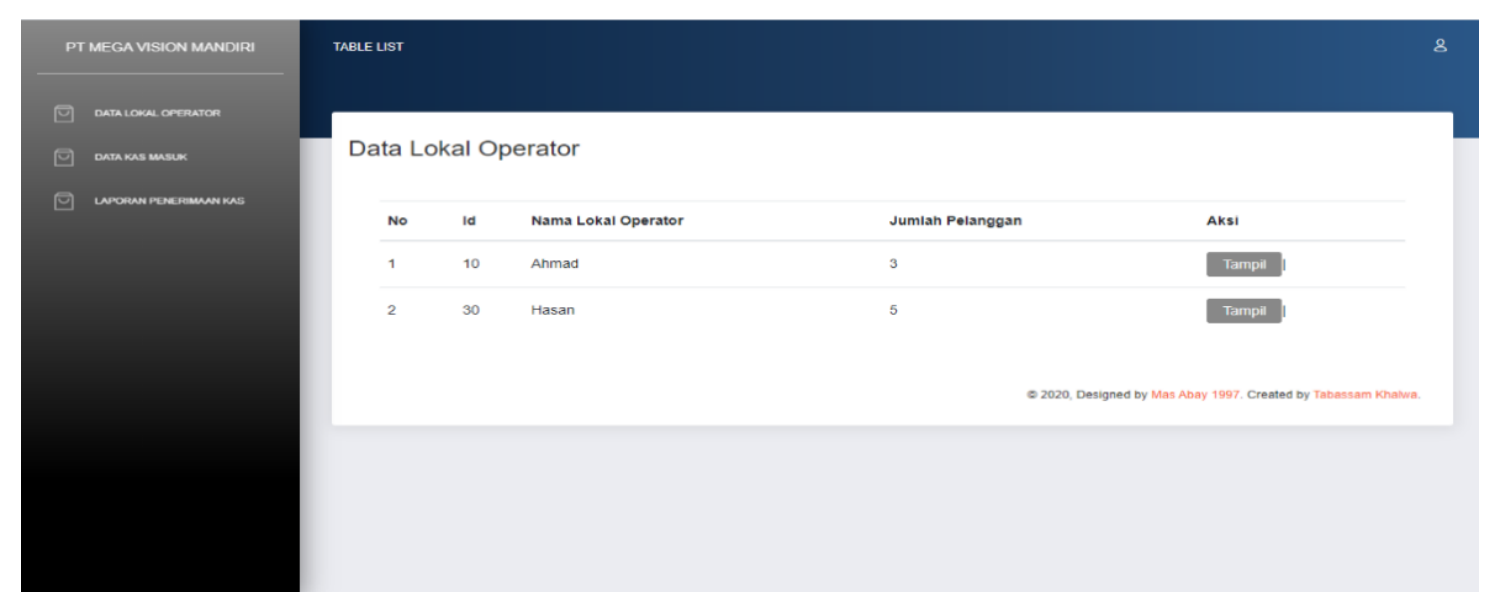

Gambar 11. Tampilan Data Lokal Operator

\subsubsection{Tampilan Menu Data Pelanggan}

Tampilan Menu Data Pelanggan yaitu data yang di gunakan oleh bagian direktur untuk melihat dan mengecek data pelanggan.

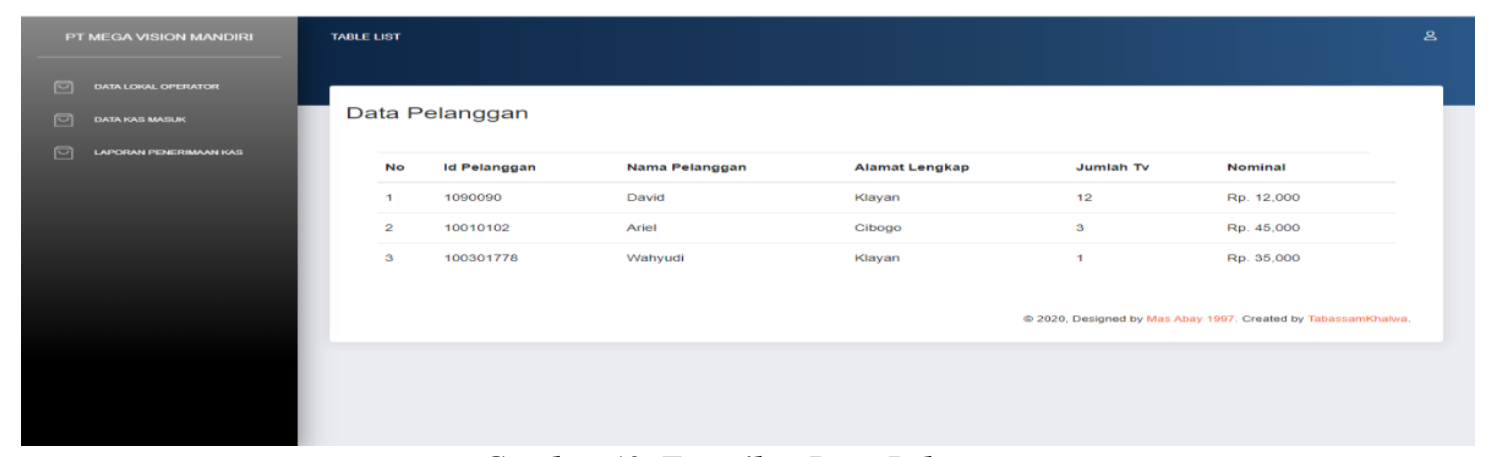

Gambar 12. Tampilan Data Pelanggan

Aplikasi Akuntansi Pencatatan Penerimaan Kas Pada PT. Mega Vision Mandiri (Ahmad Baihaqi Amir Amrullah, Widya Jati Lestari, Wanda Ilham) 


\subsubsection{Tampilan Data Kas Masuk}

Tampilan Data Kas Masuk yaitu tampilan yang di gunakan oleh bagian direktur untuk melihat dan mengecek data kas masuk.

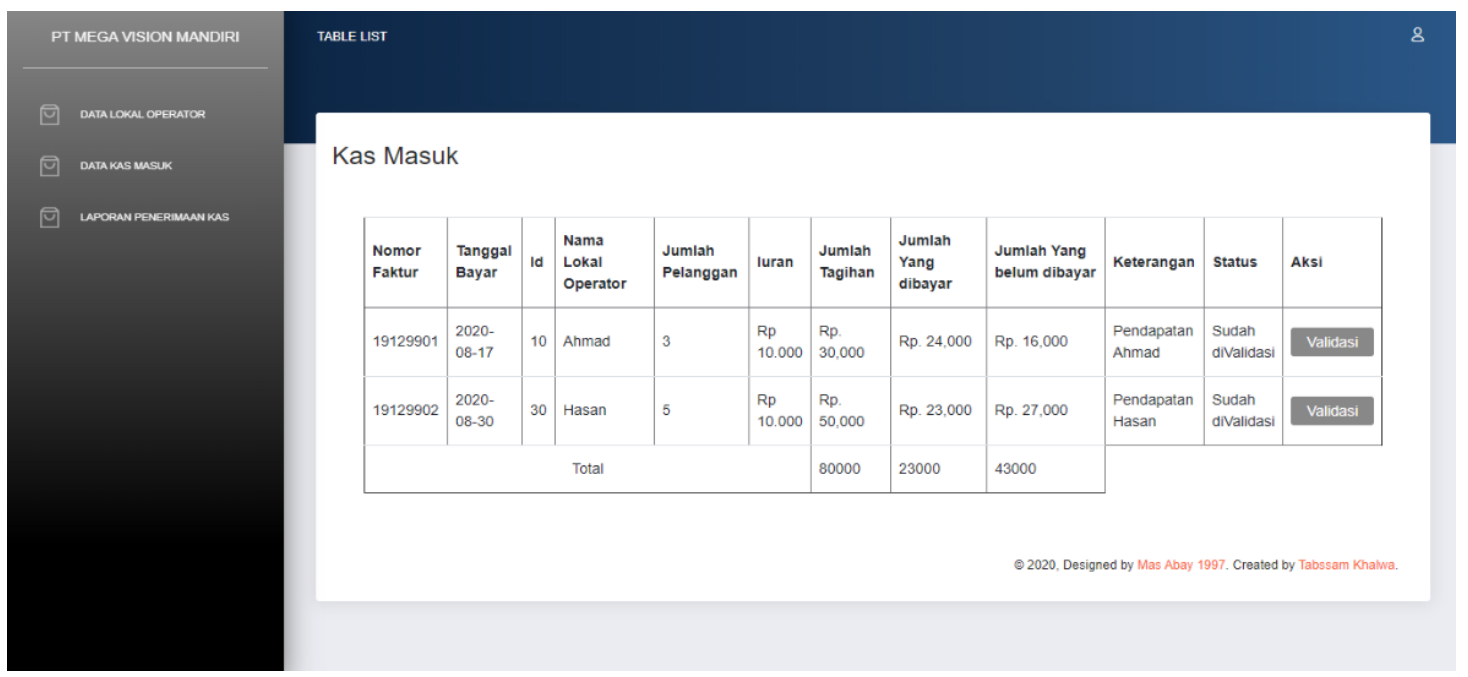

Gambar 13. Tampilan Data Kas Masuk

\section{KESIMPULAN DAN SARAN \\ 5.1 Kesimpulan}

Kesimpulan yang diperoleh setelah melalui pembuatan aplikasi akuntansi pencatatan penerimaan kas pada PT Mega Vision Mandiri adalah sebagai berikut:

1. Dengan dibuatnya aplikasi akuntansi penerimaan kas berbasis web pada PT. Mega Vision Mandiri ini, maka pengguna dapat membuat catatan penerimaan kas.

2. Dengan aplikasi akuntansi penerimaan kas yang telah dibuat ini pengguna dimudahkan dalam pengelolaan penerimaan kas.

3. Penerapan pengendalian internal pada aplikasi akuntansi penerimaan kas ini terdapat 3 bagian yang memiliki tugas yang terpisah.

\subsection{Saran}

Agar Aplikasi Akuntansi Penerimaan Kas pada PT. Mega Vision Mandiri berjalan dengan baik maka penulis memberikan saran untuk memperbaiki hal-hal yang masih kurang pada aplikasi yang telah dibuat seperti :

1. Diharapkan dengan adanya aplikasi ini dapat dikembangkan lagi yaitu dengan adanya nomor faktur yang tidak diinput manual agar setiap nota yang dikeluarkan dapat dipertanggung jawabkan jika terjadi kekeliruan.

2. Diharapkan pada aplikasi ini dibuatkan buku laporan tagihan pelanggan milik lokal operator.

\section{DAFTAR PUSTAKA}

[1] Dayani, Dewi. Penerapan Sistem Akuntansi Penerimaan dan Pengeluaran Kas Pada BMT AsSalam. 2013. Program Studi Akuntansi Diploma III FE Universitas Negeri Yogyakarta.

[2] Esteria, Ni wayan, Harijanto Sabijino, Linda Lambey. Analisis Sistem Akuntansi Penerimaan dan Pengeluaran Kas pada PT. Hasjrat Abadi Manado. Jurnal Berkala Ilmiah Efisiensi, Volume 16 No. 04 Tahun 2016.

[3] Listiawati, Indah, Marsani Asfi, Rahimah Bawai. Aplikasi Sistem Akuntansi Penerimaan dan Pengeluaran Kas dengan Accrual Basic System (Studi Kasus: Instalasi Farmasi Klinik Bersalin Permata Bunda Syariah Cirebon. JURNAL DIGIT, VOL.5, NO.2 November 2015, pp.171 183.

[4] Mulyadi. 2016. Sistem Akuntansi - edisi ke 4. Jakarta: Salemba 4. 
[5] Orlando, Erick. Aplikasi Pengajuan Cuti Pada Human Resource Management Menggunakan PHP dan MYSQL ( Studi Kasus Pada PT. INTILOKA). Jurnal Ilmiah Komputasi, Volume 16 No:13,Desember 2017,p-ISSN 1412-9434/e- ISSN 2549-7227

[6] Suroso. Sistem Informasi Akuntansi Penerimaan dan Pengeluaran Kas pada PT. Sinar Galuh Pratama. Jurnla Ilmiah “Dunia Ilmu”, Vol.2 No.1 Maret 2016. 